\title{
On development of nanostructured clads using microwave energy
}

\author{
Sunny Zafar and Apurbba Kumar Sharma* \\ Mechanical and Industrial Engineering Department, \\ Indian Institute of Technology Roorkee, Roorkee-247 667, Uttrakhand, India \\ *Email: akshafme@iitr.ac.in, akshafme@gmail.com
}

Recent advances in techniques for deposition of thin films have enabled the design and manipulation of properties often unachievable with bulk materials. These improvements have been achieved using nanostructured materials. Generally coatings with high hardness and wear resistance are required in wear resistant applications [1]. Further, by engineering nanocomposite coatings, it is possible to obtain properties that cannot be achieved through single-phase material [2]. The nano sized reinforcing particles help in pinning dislocations, thereby dramatically enhancing the wear resistance. Further, nanostructured coatings/clads offer significant improvement in other properties such as thermal shock resistance and fracture toughness. The present work is concerned with application of microwave energy to develop nanostructured clads for wear resistant applications. Absorption of microwave energy is largely dependent on the skin depth of the materials $[3,4]$. Nanomaterials exhibit increased surface area, thus offer more to couple with microwave radiation. Generally, for coarse powder particles, the heating is confined to the outer layer (skin depth), and the heat transfer into the particle/material takes place through conventional modes of heat transfer. As the powder particle size decreases, more uniform heating is obtained as shown in Figure 1.

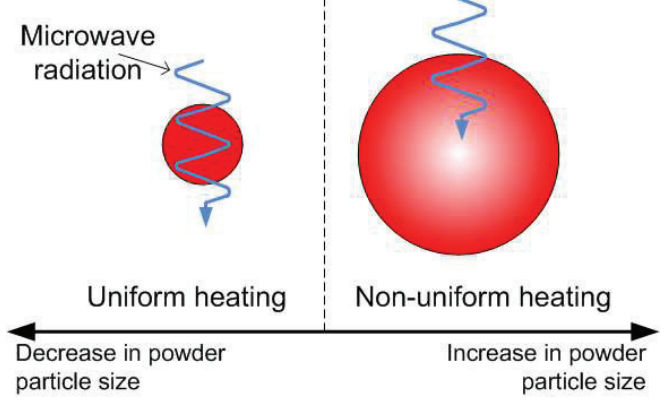

Figure 1: Microwave heating as function of size of the powder particle (adapted from [4])
In the present work nanostructured $\mathrm{WC}-12 \mathrm{Co}$ clads were developed through microwave energy at $2.45 \mathrm{GHz}$. The size effect of the target material in a microwave field has been explored. Formation of nanostructured clads through microwave cladding has been explored. Further characterisations of the nanostructured WC-12Co clads using microwave energy has been discussed.

The microstructure of the nanostructured WC12Co microwave clad is illustrated in Figure 2. The average thickness of the clad layer was 1 $\mathrm{mm}$. The developed clad was metallurgically bonded and free from interfacial cracks and solidification cracking. WC nanocarbides particles on the boundary of $\mathrm{Fe}-\mathrm{W}-\mathrm{Cr}$ matrix are clearly identified in Figure 2.

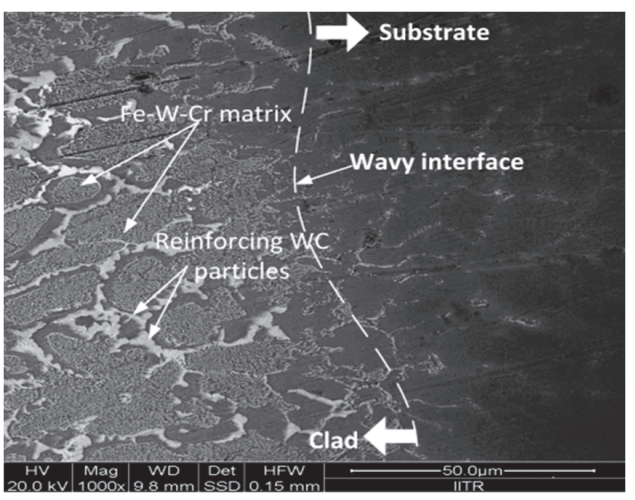

Figure 2: A typical SEM micrograph of nanostructured WC-12Co microwave clad

\section{References}

1. J. He, J.M. Schoenung, Mater. Sci. Eng. A. 336 (2002) 274-319.

2. J. Musil, Surf. Coatings Technol. 125 (2000) 322330 .

3. A.K. Shukla, A. Mondal, A. Upadhyaya, Sci. Sinter. 42 (2010) 99-124.

4. R.R. Mishra, A.K. Sharma, Compos. Part A Appl. Sci. Manuf. 81 (2015) 78-97. 